\title{
PENGGUNAAN UNGKAPAN BASA BASI \\ DALAM BAHASA JEPANG
}

\author{
Ni Made Andry Anita Dewi, \\ Ni Luh Putu Ari Sulatri \\ Program Studi Sastra Jepang, \\ Fakultas Ilmu Budaya, Universitas Udayana
}

\begin{abstract}
Abstact
Japanese society in everyday life cannot be separated from relations of communication between members of the community itselft. Based on the phenomenon of the society, it can be ascertained that courtesy is the most important thing in it. For that reason, the Japanese society functioning courtesy to achieve a good and communicative speech. The purpose of this study is to describe and analyze the functions of courtesy attached that contained in Japanese speech based on the theory of functions proposed by Leech. The data used in this study is novel titled Beautiful Life by Eriko Kitagawa. Some functions of courtesy such inhibitions were found in this study is to express a greeting, excited feelings, prise and offering something.
\end{abstract}

Key word: Japanese courtesy, courtesy function, Japanese greetings

\section{PENDAHULUAN}

Dalam bahasa Jepang, fungsi ungkapan basa basi cukup banyak ditemukan. Diantaranya berfungsi untuk mengungkapkan salam seperti ucapan salam yang digunakan sehari-hari oleh penuturnya, diantaranya: ohayou gozaimasu 'selamat pagi', konnichiwa 'selamat siang', dan o-hisashiburi 'lama tidak berjumpa'. Selain itu, fungsi ungkapan basa basi juga berfungsi untuk menawarkan sesuatu misalnya douzo o-meshi agari kudasai 'silakan makan (bentuk hormat)', kouhii ya o-cha wa ikaga desu ka 'bagaimana jika (saya) sajikan kopi atau teh hijau?'. Selain itu, fungsi penggunaan ungkapan basa basi pun cukup bervariasi diantaranya digunakan untuk memuji, memberi salam, menyatakan rasa simpati, terima kasih, suka cita, duka cita, dan lain sebagainya.

Beragamnya bentuk maupun fungsi ungkapan basa basi yang terdapat dalam bahasa Jepang baik yang digunakan dalam lingkungan tempat tinggal maupun lingkungan kerja, menarik untuk dikaji. Variasi fungsi penggunaan ungkapan basa basi ini dapat diteliti pula dari latar belakang peserta tutur yang terlibat dalam tuturan tersebut. Latar belakang peserta tutur yang dimaksud adalah seperti jarak kedekatan hubungan antar peserta tutur, posisi peserta tutur, gender, dan usia. Hal tersebut di atas secara langsung maupun tidak langsung sangat memengaruhi kesantunan berbahasa dalam bahasa Jepang.

Penelitian mengenai basa basi juga pernah dilakukan oleh Simanjuntak (2005) dalam tesisnya yang berjudul "Basa-basi dalam Bahasa Batak Toba: Sebuah Kajian Bentuk, Fungsi dan Makna”. Simanjuntak mengklasifikasikan basa-basi dalam bahasa Batak Toba dalam bentuk, fungsi dan makna. Dalam penelitiannya, Simanjuntak menyatakan ada beberapa fungsi basa basi dalam bahasa Batak Toba seperti: untuk mengungkapkan perasaan terima kasih, rasa suka cita, dan penawaran sesuatu.

Pada penelitian fungsi basa basi dalam bahasa Jepang ini, peneliti menggunakan klasifikasi fungsi bahasa yang dikemukakan oleh Leech. Dalam lima klasifikasi fungsi bahasa yang dinyatakan oleh Leech, salah satunya adalah bahasa berfungsi sebagai bahasa fatis, yakni fungsi bahasa yang digunakan dengan tujuan untuk memelihara 
hubungan antar anggota masyarakat. Basa basi dalam bahasa Jepang, merupakan salah satu tuturan bahasa yang memenuhi fungsi tersebut.

Data-data yang dianalisis pada penelitian ini bersumber pada novel bahasa Jepang yang berjudul Beautiful Life karya Eriko Kitagawa. Penelitian ini juga diharapkan dapat memperkaya penelitian di bidang kebahasaan khususnya pragmatik.

Tahap penelitian ini mencakup tahap penyediaan data, analisis data dan penyajian hasil analisis data. Tahap penyediaan data dilakukan melalui pengelompokan data yang berkaitan dengan fungsi basa basi bahasa Jepang. Metode padan intralingual dan ekstralingual diterapkan pada tahap analisis data, sedangkan metode informal digunakan pada tahap penyajian hasil analisis data.

\section{PEMBAHASAN}

\subsection{Fungsi Basa Basi untuk Mengungkapkan}

\section{Salam}

Fungsi basa basi untuk mengungkapkan salam cukup banyak ditemukan. Adapun fungsi basa basi yang digunakan adalah ucapan salam yang berkaitan dengan (1)waktu; (2)pertemuan; (3) permintaan maaf; (4)ungkapan terima kasih; (5) ungkapan saat menerima barang; (6)ungkapan saat memasuki rumah; (7)ungkapan sesudah makan; (8)ungkapan selamat atas sesuatu hal; (9)ungkapan saat seseorang selesai mengerjakan sesuatu; (10)ungkapan sebelum tidur.

\section{1) Ucapan salam berkaitan dengan waktu}

Data 1

"Konnichiwa", gogo ichiban no kyaku wa Miyama datta.

"...Konnichiwa"

“Doumo",Miyama wa karite ita "Gankutsuo" wo henkyaku suru.

"Iie", Kyouko wa kauntaa no oku ni hon wo okinïku. Miyami wa sono senaka ni ichirei shite katte itta.

(Byuutifururaifu, 2000:71)

Terjemahan:

"Selamat siang", pada sore hari, tamu yang pertama datang adalah Miyama.

"Selamat siang"

"Makasih", Miyama mengembalikan buku "Gankutsuo" yang telah dipinjamnya.

"Sama-sama", Kyoko tengah kesulitan meletakkan buku di balik rak. Miyama membungkuk kepada Kyoko lalu bergegas pergi.

Ucapan salam konnichiwa yang diucapkan oleh penutur di atas merupakan ucapan salam dalam bahasa Jepang yang diucapkan pada antara waktu sebelum siang hingga sore hari, yaitu sekitar pukul 11 siang sampai pukul 6 malam. Waktu sore hari yakni waktu antara matahari mulai terbenam sampai malam datang.

Pada data di atas digambarkan bahwa Miyama merupakan tamu pertama yang berkunjung ke perpustakaan tempat Kyoko bekerja. Sapaan yang digunakan Miyama terhadap pegawai perpustakaan yang bernama Kyoko adalah konnichiwa merupakan salam yang dapat digunakan dalam situasi formal ataupun nonformal.

Data 2

Shuuji ga monku wo itta toki, tenchou ga haitte kita.

\section{"Ohayou gozaimasu!"}

"Ee, kyou wa, minna ni ï shirase ga aru. Raigetsu, Azabu no raibu hausu wo karite, raibu wo yamerou to omoun $d a "$

(Byuutifururaifu, 2000:140)

Terjemahan:

Pada saat Shuji mengeluh, tiba-tiba pemilik toko datang. "Selamat pagi! Hari ini ada pengumuman yang bagus untuk kalian semua. Bulan depan, saya akan meminjam ruang live house Azabu, dan bermaksud menutup ruang yang kita pakai sekarang”.

Ucapan salam ohayou gozaimasu yang diucapkan oleh penutur di atas merupakan ucapan salam dalam bahasa Jepang yang diucapkan pada pagi hari hingga tengah hari sekitar pukul 11 siang. Ucapan salam ini kadangkala diucapkan pada siang hari hingga sore hari, apabila penutur baru bertemu dengan lawan tutur pertama pada hari itu. Ucapan salam ohayou gozaimasu dapat divariasikan 
menjadi bentuk ohha, dan ohayou. Ucapan ohha pada umumnya diucapkan oleh penutur golongan usia muda terhadap lawan tutur yang seusia dan memiliki hubungan kedekatan, sedangkan ucapan salam ohayou merupakan bentuk nonformal dari ohayou gozaimasu. Bentuk ohayou dapat digunakan oleh penutur dari berbagai kalangan usia namun biasanya diucapkan terhadap lawan tutur yang memiliki hubungan yang dekat.

Pada data di atas, pemilik toko menggunakan ucapan salam ohayou gozaimasu terhadap para karyawannya karena tengah berada dalam lingkungan kerja yang terkesan sedikit formal.

\section{2) Ucapan salam berkaitan dengan per- temuan \\ Data 3}

"Konnichiwa", sawayaka na egao ga furimuku.

"Tetsu chan? Yada, oshite oshite"

Kyouko ni sekasare, Miyama wa dadada to kuruma isu woo shite hashite iku.

\section{"Hisashiburi!"}

\section{"Genki sou da ne!"}

“Genki yoo. Tetsu chan wa? Ima demo basuketo ka yatteru no?”

"Iya, shigoto isogashikute"

(Byuutifururaifu, 2000:150)

Terjemahan:

“Halo!"sosok wajah segar tersenyum menoleh kearahnya.

"Tetsu? Ayo, dorong-dorong", Miyama dengan terburu-buru mendorong kursi roda sambil berlari saat diminta oleh Kyoko.

"Lama tidak bertemu!"

"Kelihatannya kamu sehat-sehat saja"

"Ya, aku sehat. Tetsu, sampai sekarang kamu masih main basket?"

"Enggak. Karena sibuk dengan pekerjaan"

Seperti pada data 1 di atas, ucapan salam konnichiwa pada data 3 juga digunakan sebagai ucapan salam saat bertemu dengan seseorang tanpa memperhatikan waktu (pagi, siang, sore maupun malam). Salam konnichiwa ini digunakan oleh berbagai penutur pada semua usia. Namun, salam ini tidak dapat digunakan untuk menggantikan bahasa ragam hormat.
Ucapan salam hisashiburi atau o-hisashiburi, digunakan oleh penutur untuk menyampaikan perasaan lama tidak bertemu dengan lawan tutur. Dalam bahasa Indonesia, salam ini bisa dipadankan dengan 'lama tidak berjumpa'. Oleh karena itu, ungkapan ini tidak digunakan oleh pembicara yang seringkali bertemu. Bentuk hormat hisashiburi adalah o-hisashiburi.

Pada data 3 di atas, digambarkan bahwa Kyoko dan Tetsu merupakan kawan lama namun sudah cukup lama tidak bertemu, oleh karena itu mereka menggunakan ungkapan basa basi untuk menanyakan keadaan (kabar) hisashiburi tersebut. Dalam masyarakat Jepang, ungkapan basa basi hisashiburi atau o-hisashiburi sering digunakan sebagai salam pertemuan antara penutur dan lawan tutur yang dalam waktu lama tidak berjumpa.

\section{3) Ucapan salam berkaitan dengan ungka- pan permintaan maaf}

Data 4

"Moushiwake arimasen ga, kore wa kashidashi kinshi to natte orimasu. Toshokan naka de no etsuran nomi desu”. Kaado to hon no baakoodo wo yomitotte ita Kyouko wa tokui sou ni Shuuji wo miageta.

"Ja, kopi kikai aru?"

"Achira ni narande kudasai", achira, to iwareta kata wo furimuku to, chouda no rei datta.

(Byuutifururaifu, 2000:7)

Terjemahan:

"Mohon maaf, buku ini tidak boleh dipinjamkan. Namun hanya untuk dibaca di dalam perpustakaan saja”, Kyoko mengambil kartu dan barcode buku sambil memandang kearah Shuji dengan angkuh.

"Kalau begitu, ada mesin fotokopi?"

"Silakan antre di sana", arah yang dikatakan 'disana', ketika dilihat adalah antrean yang sangat panjang.

Ucapan salam moushiwake arimasen, merupakan salah satu permintaan maaf yang sering digunakan penutur bahasa Jepang. Namun, ucapan salam ini biasanya digunakan oleh penutur yang memiliki hubungan yang tidak dekat dengan dengan lawan tutur. Pemakaian ucapan salam ini 
juga bersifat formal.

Bentuk ucapan salam moushiwake arimasen diucapkan ketika penutur melakukan kesalahan yang cukup besar terhadap lawan bicara. Selain untuk menyatakan kesalahan yang serius, ucapan salam ini juga digunakan oleh penutur yang berkerja di bidang pelayanan jasa, misalnya perhotelan, pariwisata, instansi pemerintah dan lain sebagainya.

Pada data di atas, Kyoko sebagai pegawai perpustakaan tidak mengizinkan Shuji untuk meminjam sebuah buku dikarenakan peraturan yang berlaku di perpustakaan itu. Bentuk permintaan maaf moushiwake gozaimasen merupakan ungkapan basa basi yang digunakan dalam pelayanan umum kepada masyarakat. Ungkapan basa basi ini mengandung unsur kesopanan yang tinggi dan terkesan ada jarak yang muncul antara penutur dan lawan tutur.

\section{4) Ucapan salam berkaitan dengan ungka- pan terima kasih}

Data 5

"Ne", Kyouko wa zasshi to kaado no baakoodo wo yomitorinagara iu. “Un?”."Anata, sou iu toko naoshita hou ga ii yo. Hito no seii, warau you na toko”. “Sou?....Suimasen. Sankyu!”, Shuuji wa sunao ni hansei shite hito koto ayamaru to, hon wo uketotte deguchi ni mukatta.

(Byuutifururaifu, 2000:55)

Terjemahan:

"Hei", Kyoko berkata sambil membaca barcode kartu dan majalah."Ya". "Kamu, sebaiknya memperbaiki hal itu. Ketulusan seseorang, yang kamu tertawakan". "Oh? Maaf, thank you!", setelah menerima buku dan mengucapkan maaf serta terima kasih, Shuji melangkah menuju pintu keluar.

Penggunaan ucapan salam terima kasih dalam bahasa Jepang cukup bervariasi, diantaranya arigatou, arigatou gozaimasu, sumimasen, suimasen, dan sankyu. Diantara ucapan salam terima kasih tersebut, arigatou gozaimasu merupakan ucapan salam yang paling sopan, sedangkan ucapan salam arigatou merupakan bentuk nonformal dari arigatou gozaimasu.
Bentuk ucapan salam sumimasen dan suimasen merupakan ucapan salam yang memiliki dua makna yaitu ucapan terima kasih yang terkandung didalamnya juga permintaan maaf atas kerepotan yang telah dialami oleh lawan tutur akibat 'perlakuan' penutur.

Pada data di atas, Shuji menggunakan basa basi yang berfungsi untuk mengucapkan terima kasih atasbukuyangdipinjamkan oleh Kyoko.Oleh karena Shuji merupakan pembaca tetap di perpustakaan itu, maka hubungan pertemanan Kyoko dengan Shuji pun menjadi lebih dekat. Karena kedekatan tersebut, maka Shuji menggunakan bentuk salam ucapan terima kasih, tidak dengan bentuk yang formal, melainkan dengan bentuk nonformal seperti sankyu. Ucapan salam sankyu merupakan bahasa serapan yang berasal dari bahasa Inggris thank you. Belakangan ini, ucapan salam sankyu sering digunakan penutur usia muda.

\section{5) Ucapan salam berkaitan dengan peneri- maan barang}

Data 6

Ishi wa rentogen shashin ni utsutta kage wo sasasu."Boku no kuchi kara ikinari de wa shokku ga ookii to omottande... tada, imouto san wa rentogen wo totta dankai de, moshikashitara nani ka kizuite iru kamoshiremasen...”. “...Waza waza, arigatou gozaimasu", Masao wa fukafuka to atama wo sage, ashi wo hikizuru you ni shinsatsu shitsu wo dete itta.

(Byuutifururaifu, 2000:267)

Terjemahan:

Dokter menunjuk hasil rontgen.

"Jika dilihat dari hasil rontgen, saya kira adik Anda secara tiba-tiba mengalami guncangan yang cukup besar, dan barangkali juga sedang terluka"

"Terima kasih. Dokter sudah repot-repot membantu kami..."

Masao menundukkan kepala dalam-dalam, lalu menyeret kakinya keluar dari ruang pemeriksaan.

Ucapan salam berkaitan dengan penerimaan suatu barang ataupun suatu kebaikan dariseseorang 
pada umumnya sama seperti mengungkapkan rasa terima kasih atas bantuan yang diterima pada umumnya yaitu arigatou gozaimasu. Namun, perbedaannya adalah biasanya diikuti dengan kata bantu waza waza yang memiliki makna bahwa lawan tutur melakukan sesuatu hal bukan sekenanya saja melainkan khusus melakukannya dengan sengaja bagi penutur.

Begitu juga dengan data percakapan di atas. Masao menggunakan ungkapan basa basi waza waza, arigatou gozaimasu, yang bertujuan untuk menyampaian perasaan terima kasih yang mendalam atas bantuan dokter untuk merawat adiknya yang sakit keras. Dengan adanya ungkapan waza waza tersebut, maka sebuah tuturan akan terkesan lebih menghormati dan menghargai segala upaya atau hal yang telah dilakukan oleh lawan tutur.

\section{6) Ucapan salam saat memasuki rumah}

\section{Data 7}

“A, okaeri!", akari no tsuita heya to, Kyouko no akarui egao ga Shuji wo demukaeta.

"Kitetan da" chotto Shuuji no kimochi ga kouba shita.

(Byuutifururaifu, 2000:67)

Terjemahan:

"Selamat datang (kembali ke rumah)"

Dengan wajah yang sangat ceria dan berseriseri, Kyoko menyambut kedatangan Shuji.

"Aku datang", terlihat Shuji pun datang dengan perasaan yang bahagia.

Dalam masyarakat Jepang, ada ungkapan basa basi yang digunakan saat menyambut seseorang kembali ke rumah. Ucapan salam tersebut adalah okaerinasai 'selamat kembali (pulang ke rumah)". Salam ini biasanya ditujukan kepada seseorang atau lawan tutur yang juga tinggal di rumah tersebut, atau orang yang dianggap keluarga dan sering berkunjung ke tempat itu.

Begitu pula yang tergambar dalam data di atas. Kyoko dengan perasaan gembira menyambut kedatangan kekasihnya yaitu Shuji. Karena Shuji cukup sering berkunjung ke rumah Kyoko, maka selayaknya keluarga sendiri, Kyoko pun menggunakan ungkapan salam okaeri terhadap
Shuji. Salam okaeri merupakan bentun nonformal dari okaerinasai.

\section{7) Ucapan salam setelah makan}

Data 8

"Gomen ne. Watashi, osake nonjatta kara..." Machida saketen no kuruma ni norikonde iru Shuuji ni, Kyouko wa okutte ikenai koto wo ayamatta.Unten seki de wa Masao ga buzen to shite iru. Yoshio to Kuniko ni, Shuuji wo okutte iku you ni iwareta noda. “Gochisousamadeshita”, Shuuji ga Kuniko tachi ni aisatsu suru to, Masao wa kuruma wo hasshin saseta.

(Byuutifururaifu, 2000:297)

Terjemahan:

"Maaf ya. Gara-gara saya minum sake..."

Shuji yang beranjak menaiki mobil milik toko sake Machida meminta maaf karena membuat Kyoko harus mengantarnya pulang ke rumah.

Di jok pengemudi, Masao memasang muka kesal. Ia seolah-olah disuruh Yoshio dan Kuniko untuk mengantarkan Shuuji pulang ke rumahnya.

"Terima kasih atas jamuannya"

Setelah Shuji selesai mengucapkan salam, Masao lantas mengemudikan mobilnya.

Berbeda dengan ucapan salam yang digunakan di negara lain, di Jepang masyarakatnya menggunakan ucapan gochisousamadeshita untuk menyatakan rasa terima kasih atas hidangan atau makanan yang sudah disajikan atau dihidangkan untuk penutur. Ungkapan ini diucapkan untuk menunjukkan perasaan hormat terhadap orang yang telah bersusah payah untuk memasak makanan untuk si penutur.

Begitu juga pada data 7 di atas. Shuji mengucapkan terima kasih atas hidangan yang sudah disajikan keluarga Kyoko untuk dirinya.

\section{8) Ucapan salam untuk mengungkapkan se- lamat atas sesuatu hal}

Data 9

Minna wa issei ni mochiba e sante iku. Shuuji wa jibun no katto dai no tokoro de, mise 
ni kuru mae ni kate kita hanbaaga wo kamibukuro kara dashite kaburi tsuita. Mayumi wa asarei no toki ni ita basho ni zutto tatta mama de, Shuji wo jitto mite iru. "Omedetou" toriaezu sou itte, Shuuji wa kamibukuro kara nomimono wo toridashita. "Arigatou" Mayumi wa sou itte, jibun no kimochiba ni modotta.

(Byuutifururaifu, 2000:40)

Terjemahan:

Semuanya telah meninggalkan lokasi pertunjukan. Akan tetapi Shuji masih berada di sana. Ia membuka kantong pembungkus hamburger yang ia beli sebelum ke salon, dan mulai menggigitnya di sudut salon tempat peralatan salonnya. Mayumi tetap berdiri tak beranjak.

"Selamat", Shuji mengucapkan selamat kepada Mayui sembari mengeluarkan minuman dari kantong plastik.

"Makasih", jawab Mayumi dan bergegas ke tempatnya bekerja.

Mayumi merupakan salah satu penata rambut profesional yang sering mengadakan pertunjukan. Di hari itu, Mayumi baru saja menyelesaikan satu pertunjukannya kembali. Pertunjukannya berlangsung dengan lancar dan sukses, sehingga mendapat ucapan selamat dari rekan sekerjanya yaitu Shuji.

Ucapan salam untuk mengucapkan selamat kepada seseorang, pada umumnya digunakan omedetou, atau omedetou gozaimasu. Bentuk omedetou merupakan bentuk yang lebih nonnormal dibandingkan omedetou gozaimasu. Shuji memilih menggunakan ungkapan basa basi omedetou dikarenakan dirinya dan Mayumi adalah rekan seprofesi dalam salon yang sama, maka hubungan mereka cukup dekat.

\section{9) Ucapan salam untuk menyatakan selesai mengerjakan sesuatu}

Data 10

"Otsukaresama desu. Chotto hanashi kikasete moratte ii desu ka?"hennshuusha ga chikazuite kita. Soshite kameraman ga Shuuji ni soto de shahin wo toranai ka to iu.
"Shashin, dekitara soto de toritain date. Dou suru? Mada ryoukai moratte nai desho".

Shuuji wa Kyouko ni tsutaeta".

(Byuutifururaifu, 2000:25)

Terjemahan:

"Hari yang melelahkan, ya. Oya, bisa saya bertanya?" Bapak Editor datang mendekat. Lantas, kameramen bertanya kepada Shuji apakah bisa mengambil foto Kyoko di luar.

"Kalau bisa, saya ingin memotretnya di luar. Bagaimana? Belum mendapat persetujuan darinya ya” Lalu, Shuji menyampaikannya kepada Kyoko.

Ucapan salam otsukaresama desu merupakan salam yang ditujukan kepada seseorang yang telah menyelesaikan suatu pekerjaan. Salam ini memiliki beberapa variasi seperti: otsukaresama, otsukaresamadeshita, gokurosama, gokurosamadeshita. Bentuk otsukaresama, otsukaresama desu, otsukaresama deshita merupakan ucapan salam yang ditujukan kepada orang yang kedudukannya lebih tinggi, sedangkan gokurosama, gokurosama desu, dan gokurosama deshita ditujukan kepada lawan tutur yang kedudukannya lebih rendah atau sederajat.

Otsukaresama desu sering digunakan sebagai penghargaan atas kerja keras seseorang yang telah dilakukan. Begitu juga yang dilakukan oleh bapak editor terhadap para karyawannya.

\section{0) Ucapan salam sebelum tidur \\ Data 11 \\ "Un. Ja, kyou wa yukkuri nero. Oyasumi" "Oyasumi"}

(Byuutifururaifu, 2000:228)

Terjemahan:

"Kalau begitu, ayo tidur. Selamat tidur" "Selamat tidur"

Dalam keseharian masyarakat Jepang, ucapan salam yang digunakan saat berpisah dan tidak bertemu lagi pada malam hari atau sebelum saat tidur adalah oyasumi atau oyasuminasai. Ucapan oyasumi lebih sering digunakan penutur terhadap lawan tutur yang usianya lebih muda atau memiliki kedudukan yang lebih rendah. Ucapan salam oyasuminasai merupakan ucapan salam yang 
lebih sopan dan cenderung digunakan oleh kaum wanita dan anak-anak.

Pada data di atas, oyasumi diucapkan oleh Masao dan Kyoko, yang merupakan dua kakak beradik dan memiliki hubungan keakraban yang cukup dekat, sehingga keduanya menggunakan bentuk nonformal oyasumi.

\subsection{Fungsi Basa Basi untuk Mengungkapkan}

\section{Perasaan Gembira}

Data 12

Iyo iyo shou no toujitsu. Mado no soto wa kaisei datta.

"Waa, ii tenki dane. Shuuji san kokorogakeii wa ne. Honban no me ni konna otenki"

Sasuga ni honbun mae wa tomarenakatta Shuuji no kawari ni, sakuban tsukisotte ita Kuniko ga shatto to kaaten wo akete, kimochi yosa sou ni nobi wo suru.

(Byuutifururaifu, 2000:341)

Terjemahan:

Akhirnya hari itu tiba. Di luar jendela nampak cuaca sangat cerah.

"Wah, cuacanya bagus ya. Shuji sangat beruntung. Di hari pertunjukannya, cuaca sangat bagus"

Kuniko yang menggantikan Shuji menginap di tempat pertunjukan, membuka tirai jendela dan merenggangkan sedikit badannya.

Penutur Jepang sering menggunakan keadaan cuaca sebagai salah satu bentuk ungkapan basa basi. Ungkapan basa basi waa ii tenki dane 'wah, cuaca bagus' ya merupakan salah satu ungkapan basa basi untuk menggambarkan rasa bahagia penutur.

Pada hari itu, Shuji yang merupakan kekasih Kyoko akan mengadakan pertunjukan sebagai penata rambut profesional. Karena cuaca yang bagus, maka diharapkan pengunjung yang akan datang juga akan banyak.

\subsection{Fungsi Basa Basi untuk Mengungkapkan Pujian kepada Lawan Tutur Data 13}

“Nani ka you?"'Nee, sono kami nan to ka shinai? Naka naka sugoi yo, sono atama" “...Suki de yatterun dakara, hottoiteyo" "Ore, kitte yarokka?"

(Byuutifururaifu, 2000:21)

Terjemahan:

"Kenapa?"

"Hei, model rambutmu tidak kau coba ubah?

Rambutmu itu, bagus lho" “...Sesukaku dong. Kau tak usah turut campur" "Gimana kalau aku potong?”

Pada tuturan data di atas, Shuji menggunakan ungkapan basa basi untuk menyatakan pujian terhadap Kyoko. Shuji memuji rambut Kyoko yang indah. Namun, pujian tersebut tak dihiraukan oleh Shuji.

Ungkapan basa basi naka naka sugoi yo, sono atama 'Rambutmu itu, bagus lho', digunakan Shuji untuk menarik hati Kyoko agar sesekali mengubah model rambutnya dengan tatanan rambut moderen.

\subsection{Fungsi Basa Basi untuk Menawarkan}

\section{Sesuatu}

Data 14

"Nechatta, ore..." “Tetsuya?" "Itsu net aka zenzen oboete nee" "Koohii ireyokka?"

"Aa ore, soto itte me, samashite kuru"Shuuji wa jaketto wo hikkake, sari ki naku Mayumi wo kawashi, soto he dete itta.

(Byuutifururaifu, 2000:80)

Terjemahan:

“Aku tertidur..” "Kamu begadang?” "Aku benarbenar tidak ingat" "Mau aku buatkan kopi?” "A, untukku? Aku mau keluar dulu, ingin membuat mataku terbuka” Shuji mengambil jaket dan melangkah keluar.

Pada tuturan data di atas, Shuji yang tertidur di apartemennya dikagetkan akan kedatangan Mayumi yang tiba-tiba tanpa sepengetahuan dirinya. Mayumi yang merasa sedikit bersalah karena merasa tidak sopan untuk datang seperti ini, akhirnya merasa sedikit canggung. Untuk menghindari suasana yang tidak nyaman, Mayumi menawari Shuji untuk dibuatkan kopi dengan menggunakan ungkapan basa basi "Koohii ireyokka?" "Mau aku buatkan kopi?”. Namun, 
Shuji yang merasa hubungannya dengan Mayumi telah berakhir, merasa tidak nyaman diperlakukan seperti saat hubungan mereka sebagai sepasang kekasih dahulu. Oleh karena itulah, Shuji bergegas pergi keluar rumah, meninggalkan Mayumi sendiri.

\section{PENUTUP}

Basi basi dalam bahasa Jepang memiliki beberapa fungsi dalam pemakaiannya. Fungsi basa basi tersebut digunakan untuk mengungkapkan salam, perasaan gembira, pujian dan penawaran sesuatu kepada lawan tutur. Sebagai pengungkap salam merupakan salah satu fungsi basa basi bahasa Jepang, diantaranya salam yang berkaitan dengan waktu konnichiwa 'selamat siang/halo'. Perasaan gembira juga dapat diungkapkan sebagai salah satu fungsi basa basi, diantaranya dengan mengungkapkan keadaan cuaca yang baik waa, ii tenki dane 'wah, cuacanya bagus ya'. Untuk pujian kepada lawan tutur, ungkapan (atama) naka naka sugoi yo '(rambutmu) keren lho', juga sering digunakan, sedangkan basa basi yang berfungsi untuk menawarkan sesuatu kepada lawan tutur dapat diungkapkan dengan koohii ireyokka 'mau aku buatkan kopi?'

Oleh karena bahasa Jepang memiliki tingkatan kesopanan bahasa atau yang juga dikenal dengan istilah keigo, maka variasi basa basi dalam bahasa Jepang ditemukan cukup beragam. Selain fungsi yang bervariasi, pembedaan penggunaan disesuaikan dengan situasi formal dan nonformal suatu tuturan diucapkan.

\section{UCAPAN TERIMA KASIH}

Pada kesempatan ini, penulis ingin menyampaikan terima kasih atas bantuan dan dukungan Universitas Udayana dalam penelitian yang berkaitan dengan basa basi dalam bahasa Jepang ini. Ucapan terima kasih ini, ingin penulis sampaikan kepada Bapak Rektor Universitas Udayana, Ketua Lembaga Penelitian dan Pengabdian Kepada Masyarakat (LPPM) Universitas Udayana dan Dekan Fakultas Ilmu Budaya Universitas Udayana. Penelitian ini didanai dari dana DIPA PNBP Universitas Udayana sesuai dengan Surat Perjanjian Penugasan dalam
Rangka Pelaksanaan Penelitian Nomor:1456/ UN14.1/LT/SPK/2016, tertanggal 27 Juni 2016. Penulis berharap, penelitian ini berguna dalam pembelajaran bahasa asing, khususnya bahasa Jepang.

\section{DAFTAR PUSTAKA}

Djadjasudarma,F. (1993) Metode Linguistik. Bandung: Eresco.

Daniel, Long dkk.(2006). Oyoushakaigengogaku. Tokyo: Sekaishisosha.

Hajikano, Are dkk.(2012). Nihongo Kaiwa Jouzu!. Tokyo: Ask Publishing.

Naoi, Mizuho.(2014). Keigo to Kotobazukai. Tokyo: Nihon Saabisu Manaa Kyoukai.

Hendry, Joy.(1987) Understanding Japanese Society. London and New York :Routledge.

Leech, Geoffrey N.(1983) Principles of Pragmatics. London: Longman.

Limei, Huang dan Kawamoto, Nobuyoshi. (1997) 'Comparative Study on the Difference between Chinese and Japanese Greetings-In View of the Education of Japanese Language in the People's Republic of China' dalam jurnal Nihon Taiiku Daigaku Volume 26 Nomor 2.

Mizutani, Osamu \& Nobuko. (1987) How To Be Polite In Japanese. Tokyo: The Japan Times.

Mahsun,M.S.(2005) Metode Penelitian Bahasa. Jakarta: Rajawali Pers.

Simanjuntak, Rotua Melda. (2005) 'Basabasi dalam Bahasa Batak Toba : Sebuah Kajian Bentuk, Fungsi, dan Makna'.Tesis. Denpasar:Universitas Udayana.

Sudaryanto.(1993) Metode dan Aneka Teknik Analisis Bahasa. Jakarta: Duta Wacana University Press.

Sibarani,Robert (2004) Antropolinguistik: Antropolinguistik.Medan: Penerbit Poda. 